\title{
Identification of neutrophil $\beta 2$-integrin LFA- 1 as a potential mechanistic biomarker in ANCA-associated vasculitis via microarray and validation analyses
}

\author{
Kotaro Matsumoto ${ }^{1}$, Takahiko Kurasawa ${ }^{1,2}$, Keiko Yoshimoto ${ }^{1}$, Katsuya Suzuki ${ }^{1}$ and Tsutomu Takeuchi ${ }^{1 *}$ (D)
}

\begin{abstract}
Background: Leukocyte activation by anti-neutrophil cytoplasmic antibody (ANCA) and the subsequent leukocyteendothelium interaction play a key role in the development of endothelial damage in ANCA-associated vasculitis (AAV). In contrast to that of leukocyte activation, the exact role of the leukocyte-endothelium interaction via integrin remains unclear. Here, we performed microarray and validation analyses to explore association between the expression levels of lymphocyte function-associated antigen-1 (LFA-1) and the clinical characteristics of patients with AAV.

Methods: We performed gene set enrichment analysis (GSEA) to identify the functional gene sets differentially expressed between patients with AAV and other types of vasculitis and the healthy controls (HCs). Flow cytometry was performed to validate the GSEA results. Treatment-naive patients were monitored until 24 weeks of treatment. To examine the role of LFA-1 in the neutrophil-endothelium interaction, we performed a leukocyte adhesion and transmigration assay using peripheral blood and human umbilical vein endothelial cells (HUVECs).

Results: GSEA revealed that the molecular pathways involving integrin-related genes were significantly upregulated in patients with AAV compared to that in patients with other types of vasculitis and the HCs. Flow cytometry revealed that the percentage of neutrophils expressing LFA-1 was significantly higher in patients with AAV than in those with large-vessel vasculitis or polyarteritis nodosa and the HCs. LFA-1 levels in the neutrophils were higher in patients with MPO-ANCA-positive expression than in those with a positive PR3-ANCA expression and correlated with the peripheral eosinophil count, serum rheumatoid factor titre, serum C-reactive protein levels, and the vasculitis activity score of systemic and chest components. After 24 weeks of treatment, including prednisolone, cyclophosphamide, rituximab, azathioprine, methotrexate, and/or tacrolimus, neutrophil LFA-1 expression remained high in the non-responder patients, but decreased in the responder patients. The in vitro assay showed that leukocyte migration toward HUVECs was dependent on the interaction between LFA-1 and intercellular adhesion molecule-1 (ICAM1); the migration of leukocytes was inhibited by blocking the adhesion of LFA-1 to ICAM1.

\footnotetext{
* Correspondence: tsutake@z5.keio.jp

'Division of Rheumatology, Department of Internal Medicine, Keio University School of Medicine, 35 Shinanomachi, Shinjuku-ku, Tokyo, Japan

Full list of author information is available at the end of the article
}

(C) The Author(s). 2021 Open Access This article is licensed under a Creative Commons Attribution 4.0 International License, which permits use, sharing, adaptation, distribution and reproduction in any medium or format, as long as you give appropriate credit to the original author(s) and the source, provide a link to the Creative Commons licence, and indicate if changes were made. The images or other third party material in this article are included in the article's Creative Commons licence, unless indicated otherwise in a credit line to the material. If material is not included in the article's Creative Commons licence and your intended use is not permitted by statutory regulation or exceeds the permitted use, you will need to obtain permission directly from the copyright holder. To view a copy of this licence, visit http://creativecommons.org/licenses/by/4.0/ The Creative Commons Public Domain Dedication waiver (http://creativecommons.org/publicdomain/zero/1.0/) applies to the data made available in this article, unless otherwise stated in a credit line to the data. 
(Continued from previous page)

Conclusions: The expression of LFA-1 in neutrophils is increased in patients with AAV. Neutrophil LFA-1 levels correlate with the clinical features of AAV. Inhibiting the adhesion of LFA-1 and ICAM1 impedes the neutrophilendothelium interaction and may have a therapeutic role in AAV.

Keywords: ANCA-associated vasculitis, Gene expression, $\beta 2$-integrin, Lymphocyte function-associated antigen-1

\section{Background}

Anti-neutrophil cytoplasmic antibody (ANCA)-associated vasculitis (AAV) is an autoimmune disease that affects small- to medium-sized blood vessels and includes microscopic polyangiitis (MPA), granulomatosis with polyangiitis (GPA), and eosinophilic granulomatosis with polyangiitis (EGPA) [1-3]. Neutrophils in the peripheral blood are elevated and play a central role in the pathogenesis of AAV [4-7]. Although the phenotypes and functional changes in the endothelial cells of AAV patients are not fully understood, an elevated proportion of circulating endothelial cells is associated with disease activity in AAV [8-10]. While vasculitis is associated with abnormalities in circulating immune cells and vascular endothelial cells [11-13], the exact role of the neutrophil-endothelium interaction in AAV remains unclear.

Activated leukocytes in the peripheral blood are known to display altered levels of surface molecules. For example, CD11b levels in neutrophils and monocytes are elevated, while CD62L levels in monocytes are decreased in patients with GPA [14-18]. ANCA can induce neutrophil activation via interaction with the $\alpha \mathrm{M}$ (CD11b) and $\beta 2$ (CD18) subunits of integrin Mac-1 [14, 15]. Granules from activated neutrophils and neutrophil extracellular traps stimulate endothelial reactive species and induce endothelial damage [19].

The leukocyte-endothelium interaction is essential for governing the movement of leukocytes toward the site of inflammation and regulating leukocyte recruitment. Lymphocyte function-associated antigen-1 (LFA-1) is an $\alpha \mathrm{L}$ (CD11a) and $\beta 2$ (CD18) integrin subunit, which interacts with intercellular adhesion molecule-1/2 (ICAM1/2) on endothelial cells [20-22]. We previously reported that LFA-1 is upregulated in patients with systemic lupus erythematosus with vasculitis [23]. However, the role of LFA1 in AAV is not well understood.

AAV is primarily managed with cyclophosphamide- or rituximab-based treatments; however, close to $50 \%$ of patients experience disease relapses [24-26], and a therapeutic drug that can target neutrophil activation has not yet been developed. Considering the fact that the neutrophil-endothelium interaction is an essential process [27, 28], integrin-mediated neutrophil-endothelium adhesion may act as a promising therapeutic target in AAV.

In this study, we performed a microarray analysis and validation to identify the key molecules involved in integrin-mediated cell adhesion occurring in AAV. Subsequently, we identified LFA-1 and explored its role in AAV.

\section{Patients and methods}

\section{Patients and healthy controls}

To explore the key molecule associated with the clinical characteristics of patients with AAV, we first conducted a microarray analysis and analysed the data using the Gene Set Enrichment Analysis (GSEA) and a pathway analysis (Fig. 1a). Following this, a fluorescence-activated cell sorting (FACS) analysis was performed to validate the microarray results (Fig. 1b). Whole blood samples were collected from patients at the Keio University Hospital, between April 2008 and January 2021. Patients with MPA $(n=4)$, GPA $(n=2)$, EGPA $(n=2)$, rheumatoid vasculitis (RV; $n=10)$ [29], polyarteritis nodosa $(\mathrm{PAN} ; n=2)$ [30], and Takayasu arteritis (TAK; $n=3$ ) [31], who met the respective international classification criteria, and 21 healthy controls ( $\mathrm{HCs}$ ) were enrolled in the microarray analysis. Additionally, active patients with AAV (total number $=48$; MPA, $n=20$; GPA, $n=19$; EGPA, $n=9$ ), LVV (total number $=26$; TAK, $n=11$; giant cell arteritis [32], $n=15)$, PAN $(n=4)$, and HCs $(n=17)$ were enrolled in the validation analysis. Patients with GPA were further compared between generalised $(n=15)$ and localised $(n=4)$ forms, as previously categorised [33]. We confirmed that the HCs did not report a history of any autoimmune disease, severe allergic disorder, malignancy, or infection.

This study was approved by the Institutional Review Board of Keio University School of Medicine (\#20140335) and was conducted in compliance with the Declaration of Helsinki. Written informed consent was obtained from all participating individuals.

\section{Clinical assessment}

Clinical information was obtained from patient records. Disease activity in vasculitis patients was recorded using the Birmingham Vasculitis Activity Score (BVAS) 2003, along with clinical signs [34]. Evidence of organ involvement (mucous membranes/eyes, ear, nose, throat, chest, kidney, and nervous system) and laboratory data, including the erythrocyte sedimentation rate, white blood cell count, haemoglobin level, platelet count, C-reactive protein (CRP) level, IgG level, ANCA positivity, ANCA titre, 


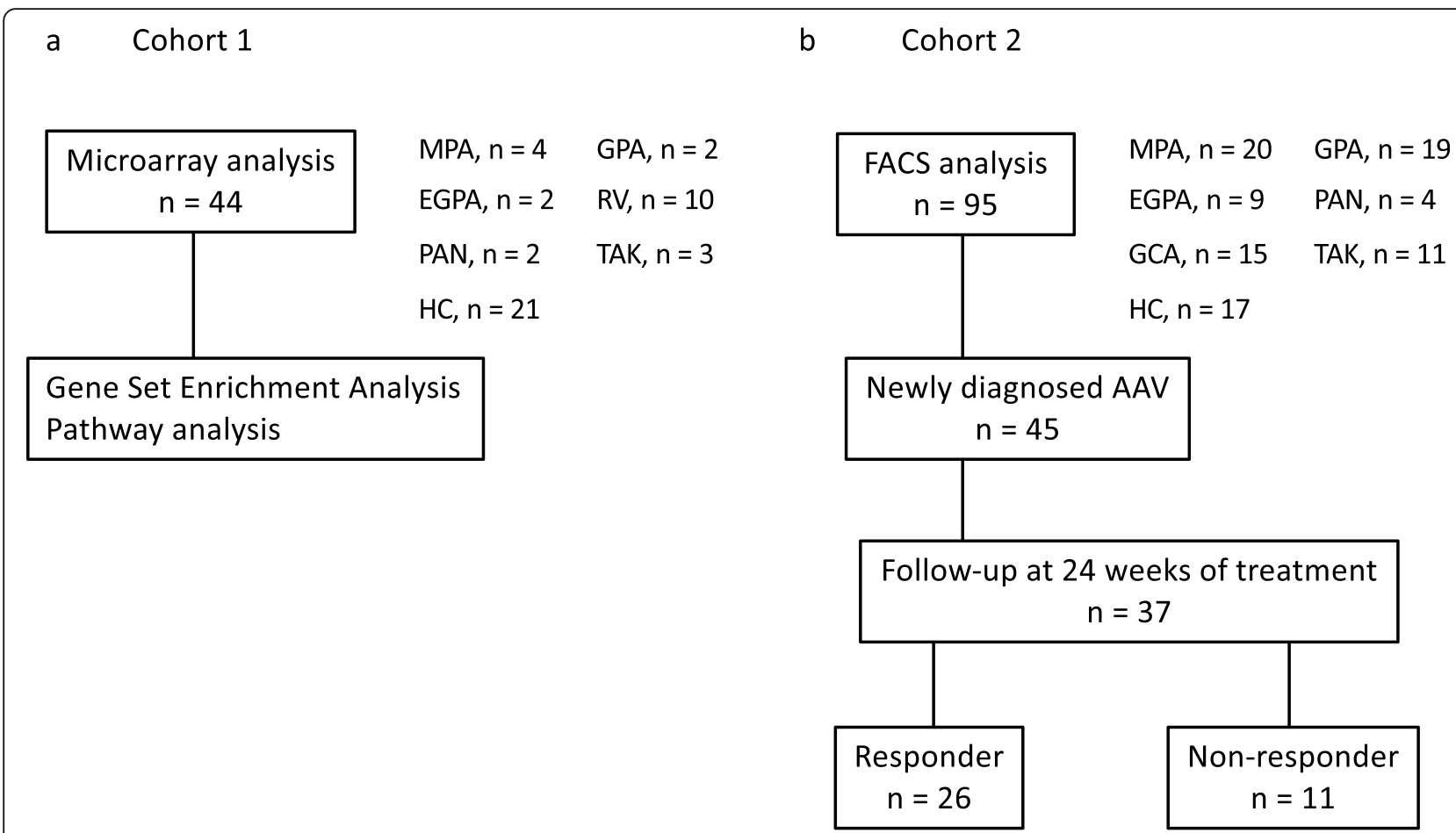

Fig. 1 Study design and analytical strategy. a Microarray analysis and $\mathbf{b}$ fluorescence-activated cell sorting (FACS) analysis for validation. AAV, antineutrophil cytoplasmic antibody-associated vasculitis; MPA, microscopic polyangiitis; GPA, granulomatosis with polyangiitis; EGPA, eosinophilic granulomatosis with polyangiitis; RV, rheumatoid vasculitis; PAN, polyarteritis nodosa; TAK, Takayasu arteritis; HC, healthy control

and rheumatoid factor (RF) levels, were assessed. Remission was defined as the absence of clinical signs in the disease activity, as indicated by a BVAS of 0 maintained for at least 2 months [26]. Patients who were treatmentnaive at the time of inclusion received treatment, including prednisolone, cyclophosphamide, rituximab, azathioprine, methotrexate, and/or tacrolimus, during the 24 weeks of follow-up evaluations. These patients were categorised into responder and non-responder groups according to whether they were in remission at 24 weeks of treatment.

\section{RNA extraction}

Blood samples were collected in the PAXgene blood RNA tubes (PreAnalytiX, Hombrechtikon, Switzerland). Total RNA was extracted using the PAXgene blood RNA kit (PreAnalytiX) according to the manufacturer's instructions. Total RNA quantity and quality were determined using a NanoDrop 1000 spectrophotometer (Thermo Fisher Scientific, Waltham, MA, USA) and an Agilent 2100 Bioanalyzer (Agilent Technologies, Santa Clara, CA, USA), respectively. All RNA samples met the following criteria: RNA integrity $>7$ and optical density at $260 / 280 \mathrm{~nm}>1.6$.

\section{Microarray experiment}

Cyanine 3-labelled complementary RNAs (cRNAs) were synthesised using the QuickAmp Labelling Kit (Agilent Technologies). The cRNAs were hybridised to the whole human genome at $65^{\circ} \mathrm{C}$ for $17 \mathrm{~h}$ using Microarray $8 \times 60$ $\mathrm{K}$ v 2.0 (Agilent Technologies). After washing, the microarrays were scanned using an Agilent DNA microarray scanner (Agilent Technologies). The intensity value for each scanned feature was extracted using the Agilent Feature Extraction software (Agilent Technologies).

\section{GSEA and pathway analysis}

We performed GSEA with v 2.1.0 (http://www. broadinstitute.org/gsea/index.jsp) using GeneSpring GX $\mathrm{v}$ 11.0.2 (Agilent technologies) to identify the functional gene sets that were differentially expressed among patients with AAV, disease controls, and HCs. Fold change (FC) was calculated to determine whether a set of genes showed statistically significant, concordant differences between two biological states. A two-sided unpaired Welch's $t$ test was performed for each pair of comparison groups, and adjusted $P$ values were calculated using the Benjamini and Hochberg correction. Statistically significant changes in proteins or metabolites were selected using an adjusted $P$ value $<0.05$ and absolute $\mathrm{FC}>1.3$. 
Pathway analysis was performed using MAPPFinder (GenMAPP, www.genmapp.org).

\section{FACS analysis}

We investigated the surface expression of the $\alpha$ - and $\beta$ integrin subunits on neutrophils, monocytes, and lymphocytes using FACS analysis. FACS analysis of the cells present in $20 \mu \mathrm{L}$ of heparinised blood samples was performed. For gating purposes, the neutrophil population was verified by staining with an anti-CD16b-PE antibody (Clone CLB-gran11.5; BD Biosciences, San Jose, CA, USA). Monocytes and lymphocytes were gated using forward-and side-scatter. The antibodies used to probe surface molecules included anti-CD11a/CD18-Fluor488 (Clone M24; BioLegend, San Diego, CA, USA), antiCD11a-PE-Cy7 (Clone HI111; BioLegend), anti-CD11bFITC (Clone M1/70; BioLegend), anti-CD11c-VioBlue (Clone 4.9; BioLegend), and anti-CD18-APC (Clone TS1/ 18 ; BioLegend). Isotype-matched control IgGs for the corresponding antibodies were used as negative controls.

The fluorescence-activated cell sorting (FACS) analysis was conducted on an MACS Quant Analyser (Miltenyi Biotec, Auburn, CA, USA) using FlowJo v 10.1. (Tree Star, Ashland, OR, USA). Details of the gating strategy are provided in Supplementary Fig. 1. We collected clinical data and peripheral blood samples from patients with AAV until 24 weeks of treatment.

\section{In vitro leukocyte adhesion and transmigration assay}

To examine the function of LFA-1 in the leukocyteendothelium interaction, we performed a leukocyte adhesion and transmigration assay using human umbilical vein endothelial cells (HUVECs) and peripheral leukocytes from HCs, as previously described [35]. HUVECs were grown in $\mathrm{EGM}^{\mathrm{m}}$-2 (Lonza, Basel, Switzerland) to $70-80 \%$ confluence and then treated with $10 \mathrm{ng} / \mathrm{mL}$ tumour necrosis factor (TNF)- $\alpha$ (PeproTech, Rocky Hill, NJ, USA) for $24 \mathrm{~h}$ to induce ICAM expression. Peripheral blood was used after haemolysis using HetaSep (Veritas, Tokyo, Japan). Subsequently, the Leuko Tracker solution (Cell Biolabs, San Diego, CA, USA) and $100 \mathrm{ng} /$ $\mathrm{mL}$ of lipopolysaccharide (LPS)-pre-treated peripheral blood $\left(1 \times 10^{5}\right.$ cells/well $)$ were loaded into the upper chamber of Transwell inserts $(3.0 \mu \mathrm{m}$ pore size, 24 -well plates; Corning, NY, USA). Recombinant interleukin (IL)-8 (10 ng/mL, PeproTech) and N-formyl-met-leuphe (fMLP) (100 nM, Sigma-Aldrich, St Louis, MO, USA) were added to the lower compartment of each well as chemoattractants. Transmigrated cells were collected after co-incubation of leukocytes and HUVECs for $2 \mathrm{~h}$ and quantified by measuring the fluorescence intensity of Leuko Tracker solution-labelled leukocytes in the culture medium. The leukocyte transmigration assay was also conducted after treatment with $10 \mu \mathrm{g} / \mathrm{mL}$ of neutralising anti-LFA-1 antibody (Clone hu1124; Novus Biologicals, Littleton, CO, USA), anti-ICAM1 antibody (Clone 1A29; Thermo Fisher Scientific), and isotypematched control IgG. The experiments were replicated in six healthy subjects.

\section{Statistical analysis}

Continuous data are expressed as median and interquartile range (IQR), and categorical data are expressed as numbers and percentages. The Mann-Whitney $U$ test was used to examine the differences between two groups, and the chi-squared test was used for nominal variables. Wilcoxon's signed-rank test was used to compare paired samples. The spearman's rank correlation coefficient was used for correlation analysis. Statistical significance was set at $P<0.05$. All analyses were performed using the $\mathrm{R}$ statistics package ( $\mathrm{v}$ 3.6.1; The $\mathrm{R}$ Foundation for Statistical Computing, Vienna, Austria), SPSS Statistics v 26.0 (IBM Corp., Armonk, NY, USA), and GraphPad Prism v 8.0 (GraphPad, La Jola, CA, USA).

\section{Results \\ Identification of characteristic molecular profile for patients with AAV}

Baseline characteristics of the patients are shown in Table 1 and Supplementary Table 1. Among the 24 patients enrolled for transcriptome analysis, six were treatment-naïve and the remaining 18 were undergoing treatment (Supplementary Table 1). We used GSEA to identify the molecular biological features of each type of vasculitis. Table 2 shows the pathways that were upregulated and downregulated in AAV, RV, PAN, and TAK, compared to those in the $\mathrm{HCs}$, using the permute $P$ value $<0.05$. At a significance threshold of the FDR adjusted $P$ value $<0.05$, and fold change $>1.3$, we identified 3770 differentially expressed genes between patients with AAV and the HCs (Fig. 2a). Among the 1765 upregulated genes, the pathways related to IL-6 (adjusted $P$ value $=0.0022)$, IL-5 (adjusted $P$ value $=0.014$ ), integrinmediated cell adhesion (adjusted $P$ value $=0.030$ ), and insulin signalling (adjusted $P$ value $=0.049$ ) were significantly upregulated in patients with AAV compared to those in the HCs; the MAPK signalling pathway tended to be upregulated in patients with AAV (adjusted $P$ value $=0.071) \quad($ Fig. $2 \mathrm{~b})$. As the leukocyte-endothelium interaction plays an important role in endothelial damage, we focused on integrin families. Regarding individual genes, the expression levels of genes associated with integrin-mediated cell adhesion (ILK, ITGAM, ITFG1, ITGB3, ITGA2B, and ITGB2) were higher in patients with AAV than in the disease controls and HCs (Fig. 2c). 
Table 1 Baseline characteristics of patients, assessed using FACS analysis

\begin{tabular}{|c|c|c|c|c|}
\hline \multirow[t]{2}{*}{ Variable } & AAV & LVV & PAN & $\begin{array}{l}\mathrm{HC} \\
n=17\end{array}$ \\
\hline & $n=48$ & $n=26$ & $n=4$ & $n=17$ \\
\hline \multicolumn{5}{|l|}{ Baseline characteristics } \\
\hline Age, years & $70(57-80)$ & $67(47-72)$ & $64(48-72)$ & $43(32-56)$ \\
\hline Male, $n(\%)$ & $15(31)$ & $14(54)$ & $1(25)$ & $5(29)$ \\
\hline Race, Japanese, $n$ (\%) & $48(100)$ & $26(100)$ & $4(100)$ & $17(100)$ \\
\hline MPA/GPA/EGPA, $n$ & 20/19/9 & - & - & - \\
\hline GCA/TAK, $n$ & - & $15 / 11$ & - & - \\
\hline Newly diagnosed/major relapse, $n$ & $45 / 3$ & $24 / 2$ & $4 / 0$ & - \\
\hline BVAS & $12(8-18)$ & $3(3-6)$ & $15(12-19)$ & - \\
\hline \multicolumn{5}{|l|}{ Organ involvement } \\
\hline Systemic, n (\%) & $34(71)$ & $23(88)$ & $2(50)$ & - \\
\hline Skin, $n(\%)$ & $5(10)$ & $1(4)$ & $3(75)$ & - \\
\hline Mucous membranes/eyes, $n$ (\%) & $5(10)$ & $0(0)$ & $0(0)$ & - \\
\hline Ear, nose, throat, $n(\%)$ & $22(46)$ & $0(0)$ & $0(0)$ & - \\
\hline Chest, $n(\%)$ & $28(58)$ & $0(0)$ & $1(25)$ & - \\
\hline Vascular, $n(\%)$ & $3(6)$ & $9(35)$ & $1(25)$ & - \\
\hline Renal, $n(\%)$ & $17(35)$ & $3(12)$ & $1(25)$ & - \\
\hline Nervous system, $n(\%)$ & $20(42)$ & $0(0)$ & $3(75)$ & - \\
\hline \multicolumn{5}{|l|}{ Laboratory test } \\
\hline $\mathrm{ESR}, \mathrm{mm} / \mathrm{h}$ & $87(40-121)$ & $109(59-122)$ & $71(33-112)$ & - \\
\hline White blood cells, $10^{3}$ cells/ $\mu \mathrm{L}$ & $9.5(7.0-13)$ & $9.5(7.0-14)$ & $7.7(6.6-9.1)$ & - \\
\hline Neutrophils, $10^{3}$ cells/mL & $6.2(4.4-8.4)$ & $5.4(4.6-7.0)$ & $6.1(2.6-8.4)$ & - \\
\hline Lymphocytes, $10^{3}$ cells/ $\mu \mathrm{L}$ & $1.5(1.0-1.8)$ & $1.4(1.1-1.8)$ & $1.1(0.8-1.6)$ & - \\
\hline Monocytes, cells/ $\mu \mathrm{L}$ & $414(308-623)$ & $460(343-565)$ & $444(235-737)$ & - \\
\hline Eosinophils, cells/ $\mu \mathrm{L}$ & $223(116-814)$ & $119(67-192)$ & $109(7-755)$ & - \\
\hline Haemoglobin, g/dL & $11(9.6-13)$ & $11(10-12)$ & $12(11-13)$ & - \\
\hline Platelets, $10^{4}$ cells $/ \mu \mathrm{L}$ & $34(25-41)$ & $34(29-42)$ & $28(18-36)$ & - \\
\hline $\mathrm{CRP}, \mathrm{mg} / \mathrm{dL}$ & $3.9(0.7-8)$ & $4.8(2.4-6.5)$ & $0.8(0.3-5.2)$ & - \\
\hline $\operatorname{lgG}, \mathrm{mg} / \mathrm{dL}$ & $1648(1120-1905)$ & $1437(1140-1690)$ & $1325(1124-2223)$ & - \\
\hline MPO-ANCA-/PR3-ANCA-positive/ANCA-negative, $n$ & $34 / 8 / 6$ & $1 / 0 / 25$ & $0 / 0 / 4$ & - \\
\hline MPO-ANCA titre, U/mL & $41(13-171), n=34$ & $28, n=1$ & - & - \\
\hline PR3-ANCA titre, $\mathrm{U} / \mathrm{mL}$ & $14(10-39), n=8$ & - & - & - \\
\hline Rheumatoid factor positive, $n(\%)$ & $37(79)$ & $2(8)$ & $1(25)$ & - \\
\hline Rheumatoid factor, IU/mL & $65(32-141)$ & $29(16-42)$ & $41, n=1$ & - \\
\hline
\end{tabular}

AAV ANCA-associated vasculitis, MPA microscopic polyangiitis, GPA granulomatosis with polyangiitis, EGPA eosinophilic granulomatosis with polyangiitis, LVV largevessel vasculitis, GCA giant cell arteritis, TAK Takayasu arteritis, PAN polyarteritis nodosa, BVAS Birmingham vasculitis activity score, ESR erythrocyte sedimentation rate, CRP C-reactive protein, MPO myeloperoxidase, $P R 3$ proteinase 3

\section{Neutrophil LFA-1 upregulation in patients with AAV}

Given that $\alpha$ - and $\beta$-integrins are preferentially expressed in human neutrophils, monocytes, and lymphocytes [20-22], we examined their surface expression using FACS analysis to confirm our GSEA results.

In concordance with our GSEA results, the percentage of neutrophils expressing LFA-1 was higher in the neutrophils of patients with AAV than in those of the disease controls and $\mathrm{HCs}$ ( $\mathrm{HC}$ vs. AAV vs. GCA vs. TAK vs. PAN; $44 \%$ vs. $34 \%$ vs. $31 \%$ vs. $41 \%$ vs. $20 \%, P=$ 0.0006 ) (Fig. 3A-a). In contrast, LFA-1 expression in the monocytes and lymphocytes was not significantly different between patients with AAV and LVV and the HCs (Fig. 3A-b and -c). Furthermore, CD11c expression in the monocytes was lower in patients with AAV than in the HCs $(52 \%$ vs. $73 \%, P=0.0007)$ (Supplementary Fig. $2 \mathrm{C}$ ). In contrast, there was no significant difference in the expression of other integrins, including CD11a 
Table 2 Results of gene set enrichment analysis

\begin{tabular}{|c|c|c|c|c|c|c|}
\hline & MAPP name & Number changed & Number measured & Number on MAPP & Permute $P$ & Adjusted $P$ \\
\hline \multirow[t]{17}{*}{$\mathrm{AAV}>\mathrm{HC}$} & IL-6 pathway & 26 & 89 & 100 & $<0.001$ & 0.0022 \\
\hline & IL-5 pathway & 25 & 63 & 69 & $<0.001$ & 0.014 \\
\hline & Integrin-mediated cell adhesion & 24 & 79 & 99 & $<0.001$ & 0.030 \\
\hline & Insulin signalling pathway & 38 & 128 & 159 & $<0.001$ & 0.049 \\
\hline & MAPK signalling pathway & 36 & 129 & 162 & 0.001 & 0.071 \\
\hline & EGFR1 pathway & 38 & 148 & 177 & $<0.001$ & 0.093 \\
\hline & Focal adhesion & 34 & 132 & 187 & $<0.001$ & 0.13 \\
\hline & MAPK cascade & 10 & 22 & 29 & 0.001 & 0.057 \\
\hline & B cell receptor pathway & 36 & 146 & 158 & 0.001 & 0.23 \\
\hline & Regulation of actin cytoskeleton & 25 & 95 & 146 & 0.005 & 0.33 \\
\hline & IL-3 pathway & 24 & 93 & 101 & 0.008 & 0.39 \\
\hline & Pentose phosphate pathway & 4 & 7 & 7 & 0.011 & 0.31 \\
\hline & Glycogen metabolism & 10 & 31 & 36 & 0.011 & 0.59 \\
\hline & Proteasome degradation & 16 & 59 & 61 & 0.014 & 0.62 \\
\hline & Cytochrome P450 & 9 & 28 & 71 & 0.016 & 0.65 \\
\hline & IL-1 pathway & 11 & 35 & 38 & 0.017 & 0.57 \\
\hline & Eicosanoid synthesis & 6 & 16 & 19 & 0.030 & 0.67 \\
\hline \multirow[t]{4}{*}{$\mathrm{AAV}<\mathrm{HC}$} & Ribosomal proteins & 27 & 86 & 88 & $<0.001$ & $<0.001$ \\
\hline & Homologous recombination & 4 & 12 & 13 & 0.012 & 0.002 \\
\hline & Inflammatory response pathway & 5 & 21 & 33 & 0.029 & 0.071 \\
\hline & Synthesis and degradation of ketone bodies & 2 & 4 & 5 & 0.035 & 0.076 \\
\hline \multirow[t]{5}{*}{$\mathrm{RV}>\mathrm{HC}$} & Proteasome degradation & 9 & 59 & 61 & $<0.001$ & 0.020 \\
\hline & Prostaglandin synthesis regulation & 4 & 20 & 31 & 0.003 & 0.099 \\
\hline & Apoptosis & 6 & 76 & 82 & 0.019 & 0.80 \\
\hline & Nucleotide GPCRs & 2 & 10 & 105 & 0.037 & 0.54 \\
\hline & Electron transport chain & 6 & 87 & 105 & 0.042 & 0.93 \\
\hline $\mathrm{RV}<\mathrm{HC}$ & Inflammatory response pathway & 2 & 21 & 33 & 0.041 & 0.84 \\
\hline \multirow[t]{4}{*}{ PAN $>\mathrm{HC}$} & Oxidative stress & 3 & 18 & 28 & 0.010 & 0.31 \\
\hline & Nucleotide GPCRs & 2 & 10 & 11 & 0.016 & 0.44 \\
\hline & Statin pathway & 2 & 12 & 20 & 0.038 & 0.64 \\
\hline & Eicosanoid synthesis & 2 & 16 & 19 & 0.048 & 0.85 \\
\hline $\mathrm{PAN}<\mathrm{HC}$ & Wnt signalling and pluripotency & 4 & 64 & 97 & 0.015 & 0.83 \\
\hline \multirow[t]{3}{*}{$\mathrm{TAK}>\mathrm{HC}$} & Apoptosis & 4 & 76 & 82 & 0.008 & 0.63 \\
\hline & Hypertrophy model & 2 & 14 & 20 & 0.014 & 0.23 \\
\hline & GPCRDB class A Rhodopsin-like & 4 & 115 & 262 & 0.049 & 0.96 \\
\hline $\mathrm{TAK}<\mathrm{HC}$ & S1P signalling & 2 & 20 & 25 & 0.038 & 0.67 \\
\hline
\end{tabular}

MAPP microarray pathway profiler, AAV ANCA-associated vasculitis, RV rheumatoid vasculitis, PAN polyarteritis nodosa, TAK Takayasu arteritis, $H C$ healthy controls

(Supplementary Fig. 2A), CD11b (Supplementary Fig. 2B), and CD18 (Supplementary Fig. 2D), between patients with AAV and the HCs.

\section{Temporal changes in LFA-1 expression in the responder and non-responder groups}

Of the 45 treatment-naive patients, 37 were monitored for at least 24 weeks following the procedure. These 37 patients were categorised as responders $(n=26)$ and non-responders $(n=11)$ based on the criteria described in the 'Patients and methods' section. LFA-1 expression in the neutrophils of non-responder patients was comparable at the onset and at 24 weeks of treatment ( $25 \%$ vs. $33 \%, P=0.90)$ (Fig. 3B-a), but decreased in the responder patients (40\% vs. $16 \%, P<$ 0.0001) during follow-up (Fig. 3B-b). The expression levels of neutrophil LFA- 1 at baseline ( $40 \%$ vs. $25 \%, P=0.11)$ and 


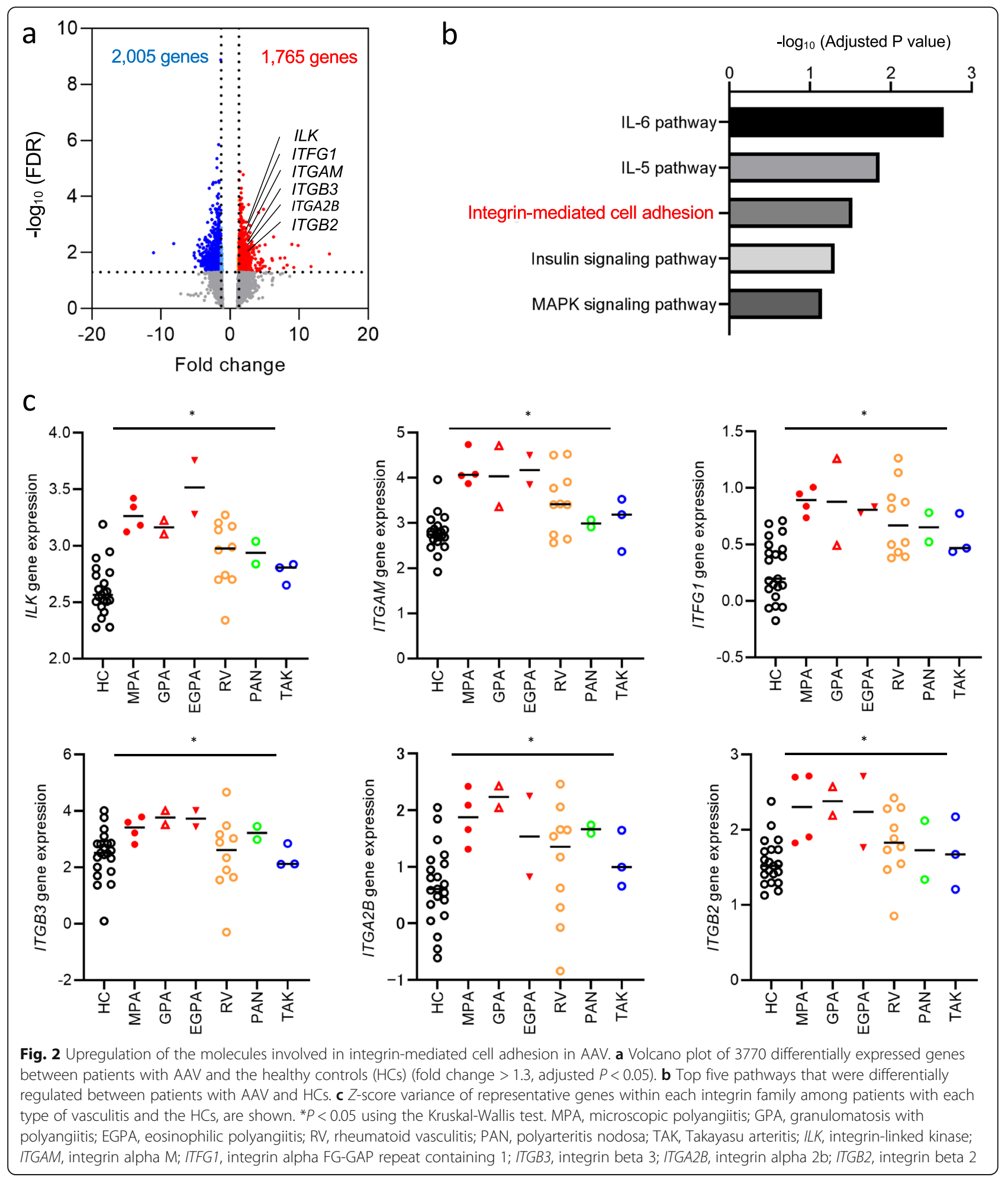

at 24 weeks of treatment $(16 \%$ vs. $33 \%, P<0.0001)$ were not significantly different between the responder and nonresponder groups. Treatments received by the responder and non-responder patients from week 0 to week 24 are shown in Supplementary Table 2.
Correlation between LFA-1 expression in neutrophils and clinical features

We compared the levels of LFA-1 with clinical phenotypes, which revealed no differences among patients with MPA, generalised GPA, localised GPA, and EGPA 


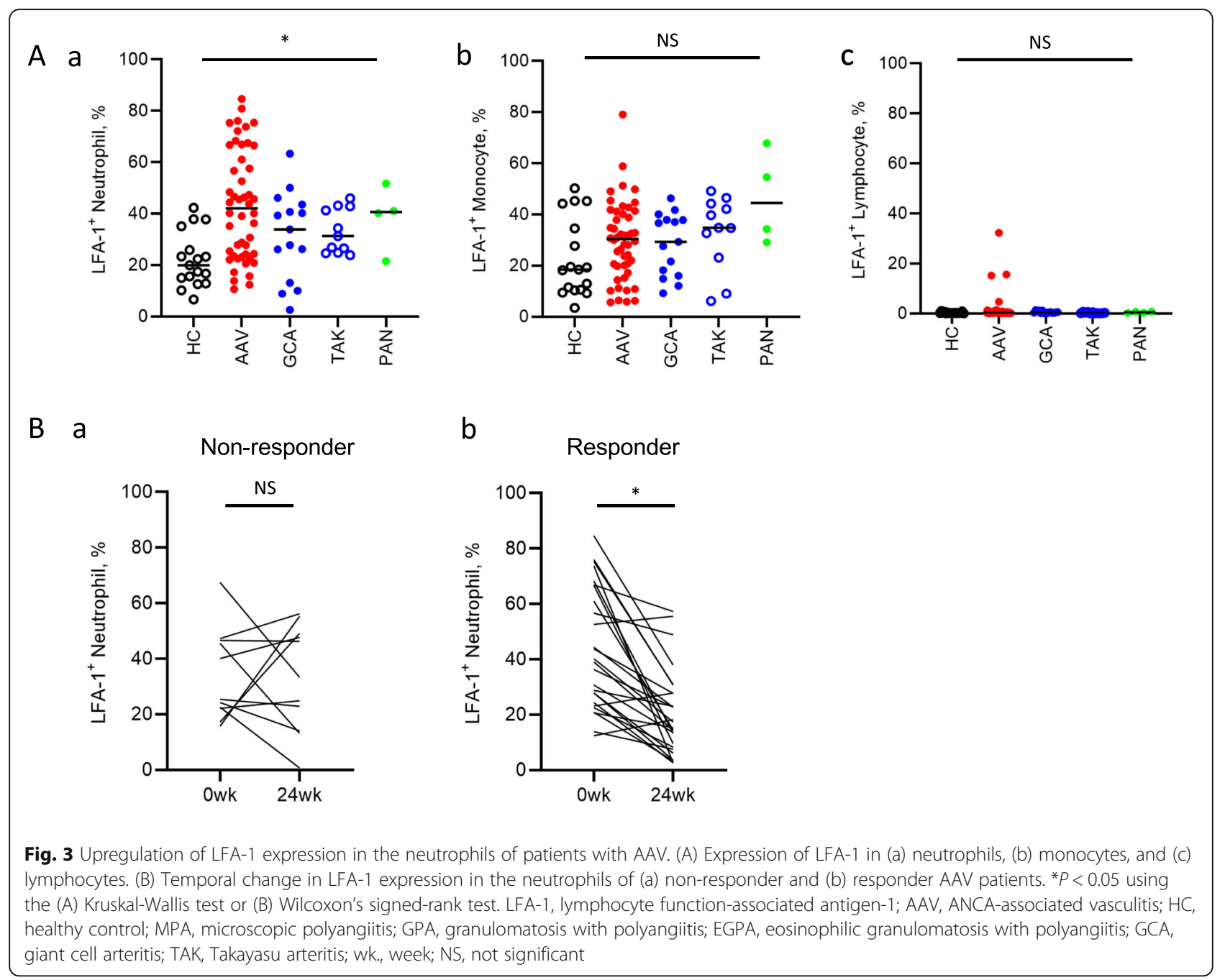

(Fig. 4A-a). The Kruskal-Wallis test and post-hoc test revealed that the levels of LFA-1 in neutrophils were comparable between patients with MPO-ANCA-positive and ANCA-negative expression, but were higher than those in patients with PR3-ANCA-positive expression (46\% vs. $48 \%$ vs. $24 \%, P=0.023$ ) (Fig. $4 \mathrm{~A}-\mathrm{b}$ ). We also examined the relationship between neutrophil LFA-1 expression levels and disease activity based on the BVAS and laboratory markers. Correlation analysis was conducted to determine the Spearman's rank correlation coefficient between LFA-1 expression in neutrophils and disease activity (Fig. 4B). Correlation analysis showed that the BVAS scores in systemic $(\rho=0.32, P=0.028)$ and chest ( $\rho=0.48, P=0.001$ ) components, excluding total BVAS and BVAS scores in other components, were significantly correlated with the expression of LFA-1 in neutrophils. Moreover, LFA-1 expression in the neutrophils was significantly correlated with eosinophil count ( $\rho=$ $0.29, P=0.048)$, serum RF level $(\rho=0.39, P=0.018)$, and serum CRP level $(\rho=0.30, P=0.038)$ in patients with
AAV. These data indicate that elevated LFA-1 expression in neutrophils may be associated with systemic disease activity in AAV.

\section{Effects of LFA-1 and ICAM1 on the leukocyte- endothelium interaction}

We performed leukocyte adhesion and transmigration assays to study LFA-1 function in the leukocyte-endothelium interaction. To avoid neutrophil activation during cell isolation, leukocytes were obtained from whole blood samples. LFA-1 was upregulated in the leukocytes after treatment with LPS (Fig. 5a), and levels of ICAM1, but not ICAM2/3, were upregulated in the HUVECs after treatment with TNF- $\alpha$ (Fig. $5 \mathrm{~b}$ ). We co-incubated LPS-stimulated leukocytes and TNF- $\alpha$-pre-treated HUVECs to examine leukocyte migration via the fluorescence intensity of Leuko Tracker solution-labelled leukocytes. We observed upregulation of LPS-pre-treated leukocyte migration toward TNF- $\alpha$-pre-treated HUVECs on a Transwell plate $\left(65 \times 10^{4}\right.$ vs. $\left.82 \times 10^{4}, P=0.031\right)$, 


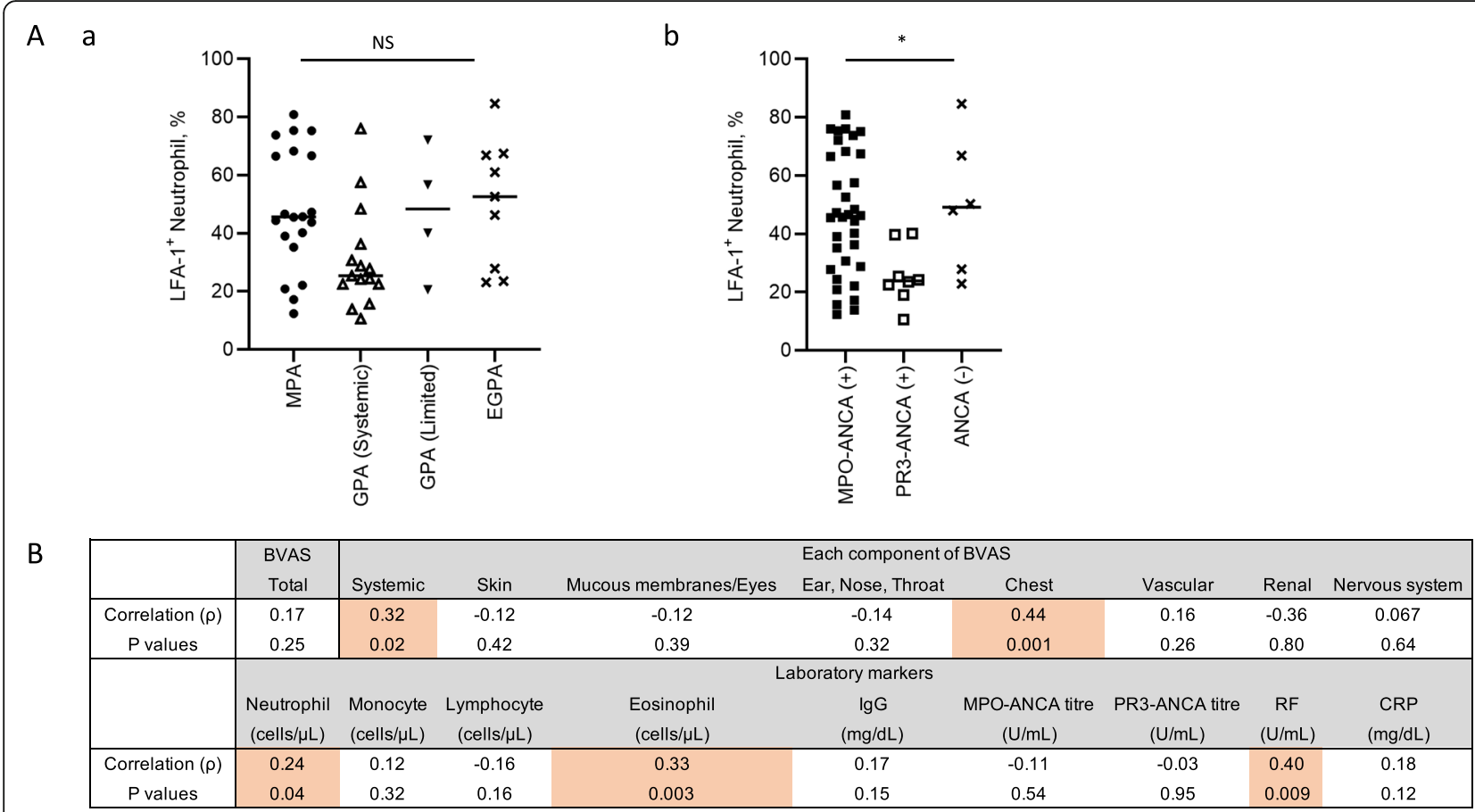

Fig. 4 Correlation between LFA-1 expression in neutrophils and disease activity. (A) Expression of LFA-1 in neutrophils among patients with (a) different disease phenotype and (b) ANCA status. (B) Correlation analysis was conducted to determine the Spearman's correlation coefficient between LFA-1 expression in neutrophils and disease activity. LFA-1, lymphocyte function-associated antigen-1; BVAS, Birmingham Vasculitis Activity Score; RF, rheumatoid factor; CRP, C-reactive protein

suggesting that the leukocyte-endothelium interaction was dependent on the expression of LFA-1 in the leukocytes and that of ICAM1 in the HUVECs (Fig. 5c). Notably, pre-incubation of leukocytes with the anti-LFA-1 and anti-ICAM1 neutralising antibodies significantly suppressed the interaction between leukocytes and HUVECs $\left(82 \times 10^{4}\right.$ vs. $\left.71 \times 10^{4}, P=0.031\right)$, whereas incubation with the isotype-matched control did not significantly affect the result $\left(82 \times 10^{4}\right.$ vs. $\left.91 \times 10^{4}, P=0.44\right)$.

\section{Discussion}

We performed a microarray analysis and GSEA to compare the molecular biological features of patients with AAV, the disease controls, and the HCs. Based on these analyses, we found that proteins of the integrin family were specifically upregulated in AAV. FACS analysis revealed that LFA-1 expression in neutrophils was significantly elevated in patients with AAV compared to that in patients with LVV and in the HCs. LFA-1 levels in the neutrophils of patients with AAV were significantly associated with systemic inflammatory markers such as eosinophil count, RF level, CRP level, and BVAS score of systemic and chest components. Interestingly, LFA-1 expression in neutrophils was higher in MPO-ANCApositive patients with AAV than in those positive for PR3-ANCA. Considering that MPO-ANCA-positive patients with AAV are at a higher risk of death [36], mechanistic biomarkers would be helpful.

The neutrophil-endothelium interaction mainly occurs due to the binding of LFA-1 to its receptor ICAM1/2 on the endothelial cells [20-22]. As neutrophil-endothelium adhesion is an essential process in neutrophil-mediated endothelial damage, upregulation of LFA-1 in neutrophils during AAV can serve as a convenient biomarker. Although the regulatory mechanism of LFA-1 expression in AAV has not yet been sufficiently explained, cytokines, such as GM-CSF and TNF$\alpha$ whose levels are elevated in patients with AAV [37], can induce LFA-1 upregulation [38].

$\beta 2$-integrins are necessary for leukocytic inflammation. JAK2-V617F knock-in mice (JAK2 ${ }^{+/ V F}$ ), which possess a JAK2 activating mutation, reportedly showed increased $\beta 2$-integrin activity in neutrophils [39]. A previous report showed that JAK2 ${ }^{+/ V F}$ mice had enhanced neutrophil-endothelium adhesion that led to pathologic thrombosis, which was inhibited by anti- $\beta 2$ integrin neutralising antibodies [39]. Abnormal functioning of integrins in leukocytes, particularly neutrophils, may induce abnormal leukocyte-endothelium interactions, contributing to such pathological events.

Integrins have recently been identified as therapeutic targets for various inflammatory diseases [40]. For example, vedolizumab, a humanised monoclonal antibody 
a

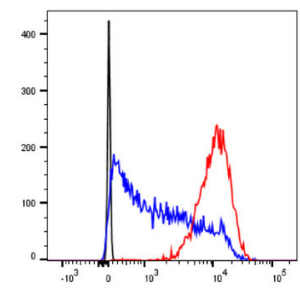

LFA-1

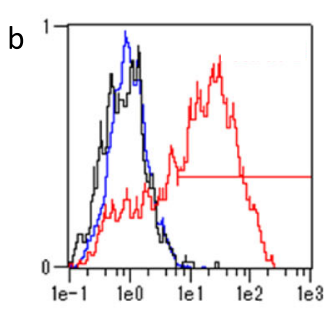

ICAM1

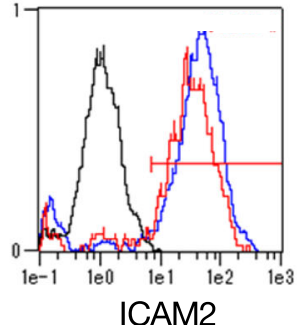

ICAM2

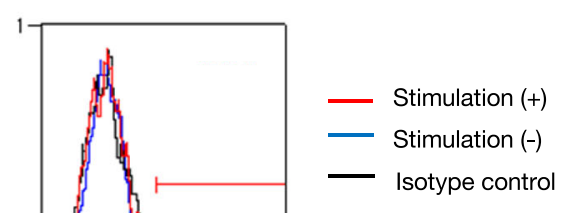

ICAM3

C

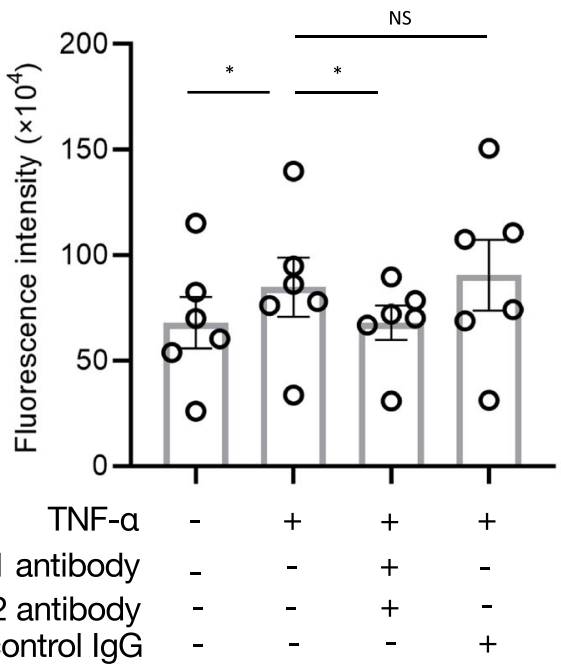

Fig. 5 Effect of LFA-1 on leukocyte-endothelium transmigration. Representative findings from flow cytometry analysis evaluating a LFA-1 expression in leukocytes and $\mathbf{b}$ ICAM1-3 expression in HUVECs in the presence and absence of LPS and TNF-a stimulation, respectively. $\mathbf{c}$ The extent of cell transmigration, as measured by the fluorescence intensity of Leuko Tracker solution-labelled leukocytes from six healthy subjects. Leukocyte migration in the presence of anti-LFA-1 antibody, anti-ICAM1 antibody, and isotype-matched control lgG was monitored. ${ }^{*} P<0.05$, using Wilcoxon's signed-rank test. LFA-1, lymphocyte function-associated antigen-1; ICAM, intercellular adhesion molecule-1; HUVEC, human umbilical vein endothelial cell; LPS, lipopolysaccharide; TNF, tumour necrosis factor

that specifically recognises the $\alpha 4 \beta 7$ heterodimer, is effective in the treatment of ulcerative colitis [41] and Crohn's disease [42]. Furthermore, natalizumab, which targets the $\alpha 4$-integrin subunit, is effective for the treatment of multiple sclerosis [43] and Crohn's disease [44]. Additionally, efalizumab, which targets LFA-1, is effective for the treatment of moderate-to-severe psoriasis [45]. However, once approved globally, it was discontinued due to an adverse event of progressive multifocal leukoencephalopathy reported in several cases [46]. In our study, LFA-1 expression in the neutrophils was upregulated in patients with AAV and was associated with systemic inflammation via the neutrophil-endothelium interaction. Thus, we believe that bispecific or multi-specific antibodies bridging LFA-1 and neutrophil surface molecules can recognise LFA-1 in neutrophils. Treatment with emicizumab, a bispecific antibody and a drug that specifically targets neutrophil LFA-1, showed a positive effect in patients with haemophilia A [47] and could be a safe and effective therapeutic alternative for AAV.

In contrast to LFA-1 expression in the neutrophils, $\mathrm{CD} 11 \mathrm{c}$ expression in the monocytes is decreased in patients with AAV. We recently reported that $\mathrm{CD}_{1} 4^{++}$and $\mathrm{CD}_{16}{ }^{+}$, which are intermediate monocytes, play a substantial role in the development of AAV [7]. As CD11c is a characteristic of both intermediate and classical monocytes [48, 49], CD11c expression may be involved in monocyte migration to the local site of inflammation; however, further investigation is needed to confirm this hypothesis.

Our study had several limitations. First, the number of patients enrolled in this study may not be sufficient to clarify the specificity of the changes in LFA-1 expression in AAV. Second, the significance of LFA-1 as a biomarker is not sufficient to distinguish between the disease controls and HCs because they overlap among groups. Third, we did not study the phenotype of endothelial cells or 
platelets in this study, although several abnormalities have been reported in the pathogenesis of AAV [50].

\section{Conclusions}

In conclusion, we demonstrated that LFA-1 upregulation may enhance endothelial damage in patients with AAV. To our best knowledge, this is the first study to identify the role of the neutrophil adhesion molecule LFA-1 in the pathogenesis of AAV. Further evidence on the mechanism of interaction between neutrophils and endothelial cells will be helpful in the identification of novel therapeutic targets for AAV treatment.

\section{Abbreviations}

ANCA: Anti-neutrophil cytoplasmic antibody; AAV: ANCA-associated vasculitis; LFA-1: Lymphocyte function-associated antigen-1; GSEA: Gene set enrichment analysis; HC: Healthy control; HUVEC: Human umbilical vein endothelial cell; LW: Large vessel vasculitis; MPA: Microscopic polyangiitis; GPA: Granulomatosis with polyangiitis; EGPA: Eosinophilic granulomatosis with polyangiitis; ICAM: Intercellular adhesion molecule; RV: Rheumatoid vasculitis; PAN: Polyarteritis nodosa; TAK: Takayasu arteritis; BVAS: Birmingham vasculitis activity score; CRP: C-reactive protein; RF: Rheumatoid factor; CRNA: Complementary RNA; FACS: Fluorescence-activated cell sorting; TNF: Tumour necrosis factor; LPS: Lipopolysaccharide; IL: Interleukin; fMLP: Nformyl-met-leu-phe

\section{Supplementary Information}

The online version contains supplementary material available at https://doi. org/10.1186/s13075-021-02510-1.

\section{Additional file 1.}

\section{Acknowledgements}

We are incredibly grateful to Ms. Yumi Ikeda, Ms. Yuko Takaishi, and Ms. Kumiko Tanaka for their technical support.

\section{Authors' contributions}

$\mathrm{KM}, \mathrm{TK}, \mathrm{KY}, \mathrm{KS}$, and $\mathrm{TT}$ designed the study. KM, TK, and $\mathrm{KS}$ were involved in patient recruitment and data collection. All the authors were involved in writing the manuscript and approved the final version. The corresponding author had full access to all data produced in the study and had final responsibility for the decision to submit for publication.

\section{Funding}

This study was supported by grants from JSPS KAKENHI (Grant Number JP20K22911), the Japan Agency for Medical Research and Development, and the Keio University School of Medicine.

\section{Availability of data and materials}

All data generated and analysed in this study are disclosed.

\section{Declarations}

\section{Ethics approval and consent to participate}

This study was approved by the Institutional Review Board of Keio University School of Medicine (\#20140335) and was conducted in compliance with the Declaration of Helsinki.

\section{Consent for publication}

Written informed consent was obtained from all participating individuals.

\section{Competing interests}

The authors have no competing interests to disclose.

\section{Author details}

1Division of Rheumatology, Department of Internal Medicine, Keio University School of Medicine, 35 Shinanomachi, Shinjuku-ku, Tokyo, Japan.

${ }^{2}$ Department of Rheumatology and Clinical Immunology, Saitama Medical

Center, Saitama Medical University, 1981 Kamoda, Kawagoe, Saitama, Japan.

Received: 4 January 2021 Accepted: 12 April 2021

Published online: 06 May 2021

\section{References}

1. Jennette JC, Falk RJ, Andrassy K, Bacon PA, Churg J, Gross WL, et al. Nomenclature of systemic vasculitides. Proposal of an international consensus conference. Arthritis Rheum. 1994;37(2):187-92. https://doi.org/1 0.1002 /art.1780370206.

2. Watts R, Lane S, Hanslik T, Hauser T, Hellmich B, Koldingsnes W, et al. Development and validation of a consensus methodology for the classification of the ANCA-associated vasculitides and polyarteritis nodosa for epidemiological studies. Ann Rheum Dis. 2007;66(2):222-7. https://doi. org/10.1136/ard.2006.054593.

3. Jennette JC, Falk RJ, Bacon PA, Basu N, Cid MC, Ferrario F, et al. 2012 Revised International Chapel Hill Consensus Conference Nomenclature of Vasculitides. Arthritis Rheum. 2013;65(1):1-11. https://doi.org/10.1002/art.3 7715 .

4. Kessenbrock K, Krumbholz M, Schönermarck U, Back W, Gross WL, Werb Z et al. Netting neutrophils in autoimmune small-vessel vasculitis. Nat Med. 2009:15(6):623-5. https://doi.org/10.1038/nm.1959.

5. Nakazawa D, Masuda S, Tomaru U, Ishizu A. Pathogenesis and therapeutic interventions for ANCA-associated vasculitis. Nat Rev Rheumatol. 2019:15(2): 91-101. https://doi.org/10.1038/s41584-018-0145-y.

6. Matsumoto K, Suzuki K, Yoshimoto K, Seki N, Tsujimoto H, Chiba K, et al. Significant association between clinical characteristics and immunophenotypes in patients with ANCA-associated vasculitis. Rheumatology (Oxford). 2020;59(3):545-53. https://doi.org/10.1093/rheumatology/kez327.

7. Matsumoto K, Suzuki K, Yoshimoto K, Seki N, Tsujimoto H, Chiba K, et al. Longitudinal immune cell monitoring identified CD14 ${ }^{++}$CD16 intermediate monocyte as a marker of relapse in patients with ANCAassociated vasculitis. Arthritis Res Ther. 2020;22(1):145. https://doi.org/10.11 86/s13075-020-02234-8.

8. Woywodt A, Streiber F, de Groot K, Regelsberger H, Haller H, Haubitz M. Circulating endothelial cells as markers for ANCA-associated small-vessel vasculitis. Lancet. 2003;361(9353):206-10. https://doi.org/10.1016/S0140-673 6(03)12269-6.

9. Woywodt A, Goldberg C, Kirsch T, de Groot K, Erdbruegger U, Haller H, et al Circulating endothelial cells in relapse and limited granulomatous disease due to ANCA associated vasculitis. Ann Rheum Dis. 2006;65(2):164-8. https://doi.org/10.1136/ard.2005.040980.

10. Schneeweis C, Rafalowicz M, Feist E, Buttgereit F, Rudolph PE, Burmester GR, et al. Increased levels of BLyS and SVCAM-1 in anti-neutrophil cytoplasmatic antibody (ANCA)-associated vasculitides (AAV). Clin Exp Rheumatol. 2010; 28(1 Suppl 57):62-6.

11. Hu P, Su H, Xiao H, Gou SJ, Herrera CA, Alba MA, et al. Kinin B1 receptor is important in the pathogenesis of myeloperoxidase-specific ANCA GN. J Am Soc Nephrol. 2020;31(2):297-307. https://doi.org/10.1681/ASN.2019010032.

12. Hu N, Westra J, Kallenberg CGM. Dysregulated neutrophil--endothelial interaction in antineutrophil cytoplasmic autoantibody (ANCA)-associated vasculitides: implications for pathogenesis and disease intervention. Autoimmun Rev. 2011;10(9):536-43. https:/doi.org/10.1016/j.autrev.2011.04.004.

13. Halbwachs $L$, Lesavre $P$. Endothelium-neutrophil interactions in ANCAassociated diseases. J Am Soc Nephrol. 2012;23(9):1449-61. https://doi.org/1 $0.1681 /$ ASN.2012020119.

14. Ramirez GA, Rovere-Querini P, Sabbadini MG, Manfredi AA. Parietal and intravascular innate mechanisms of vascular inflammation. Arthritis Res Ther 2015;17(1):16. https://doi.org/10.1186/s13075-015-0528-2.

15. Deng H, Hu N, Wang C, Chen M, Zhao MH. Interaction between CD177 and platelet endothelial cell adhesion molecule-1 downregulates membranebound proteinase-3 (PR3) expression on neutrophils and attenuates neutrophil activation induced by PR3-ANCA. Arthritis Res Ther. 2018;20(1): 213. https://doi.org/10.1186/s13075-018-1710-0.

16. Wikman A, Fagergren A, Johansson SGO, Lundahl J, Jacobson SH. Monocyte activation and relationship to anti-proteinase 3 in acute vasculitis. Nephrol Dial Transplant. 2003;18(9):1792-9. https://doi.org/10.1093/ndt/gfg216. 
17. Wikman A, Fagergren A, Forslid J, Jacobson SH, Johansson SGO, Lundahl J. Antineutrophil cytoplasmic antibodies induce decreased CD62L expression and enhanced metabolic activity in monocytes. Scand J Immunol. 2003; 57(2):179-84. https://doi.org/10.1046/j.1365-3083.2003.01209.x.

18. Day CJ, Hewins P, Savage CO. New developments in the pathogenesis of ANCA-associated vasculitis. Clin Exp Rheumatol. 2003;21(6 Suppl 32):S35-48.

19. Hong Y, Elefttheliou D, Hussain AAK, Price-Kuehne FE, Savage CO, Jayne D, et al. Anti-neutrophil cytoplasmic antibodies stimulate release of neutrophil microparticles. J Am Soc Nephrol. 2012;23(1):49-62. https://doi.org/10.1 681/ASN.2011030298.

20. Stewart M, Hogg N. Regulation of leukocyte integrin function: affinity vs. avidity. J Cell Biochem. 1996;61(4):554-61. https://doi.org/10.1002/(SICI)1 097-4644(19960616)61:4<554:.:AID-JCB8>3.0.CO;2-N.

21. Hynes RO. Integrins: bidirectional, allosteric signaling machines. Cell. 2002; 110(6):673-87. https://doi.org/10.1016/s0092-8674(02)00971-6.

22. Kolev K, West EE, Kunz N, Chauss D, Moseman EA, Rahman J, et al. Diapedesis-induced integrin signaling via LFA-1 facilitates tissue immunity by inducing intrinsic complement C3 expression in immune cells. Immunity. 2020;52(3):513-27. https://doi.org/10.1016/j.immuni.2020.02.006.

23. Takeuchi T, Amano K, Sekine H, Koide J, Abe T. Upregulated expression and function of integrin adhesive receptors in systemic lupus erythematosus patients with vasculitis. J Clin Invest. 1993;92(6):3008-16. https://doi.org/1 $0.1172 / \mathrm{JCl} 116924$

24. Flossmann O, Berden A, de Groot K, Hagen C, Harper L, Heijl C, et al. Longterm patient survival in ANCA-associated vasculitis. Ann Rheum Dis. 2011; 70(3):488-94. https://doi.org/10.1136/ard.2010.137778.

25. Jones RB, Tervaert JWC, Hauser T, Luqmani R, Morgan MD, Peh CA, et al. Rituximab versus cyclophosphamide in ANCA-associated renal vasculitis. N Engl J Med. 2010;363(3):211-20. https://doi.org/10.1056/NEJMoa0909169.

26. Stone JH, Merkel PA, Spiera R, Seo P, Langford CA, Hoffman GS, et al. Rituximab versus cyclophosphamide for ANCA-associated vasculitis. N Engl J Med. 2010;363(3):221-32. https://doi.org/10.1056/NEJMoa0909905.

27. Radford DJ, Savage CO, Nash GB. Treatment of rolling neutrophils with antineutrophil cytoplasmic antibodies causes conversion to firm integrinmediated adhesion. Arthritis Rheum. 2000;43(6):1337-45. https://doi.org/10.1 002/1529-0131(200006)43:6<1337::AID-ANR16>3.0.CO:2-M

28. Nolan SL, Kalia N, Nash GB, Kamel D, Heeringa P, Savage COS. Mechanisms of ANCA-mediated leukocyte-endothelial cell interactions in vivo. J Am Soc Nephrol. 2008;19(5):973-84. https://doi.org/10.1681/ASN.2007111166.

29. Scott DG, Bacon PA. Intravenous cyclophosphamide plus methylprednisolone in treatment of systemic rheumatoid vasculitis. Am J Med. 1984;76(3):377-84. https://doi.org/10.1016/0002-9343(84)90654-5.

30. Lightfoot RW Jr, Michel BA, Bloch DA, Hunder GG, Zvaifler NJ, McShane DJ, et al. The American College of Rheumatology 1990 criteria for the classification of polyarteritis nodosa. Arthritis Rheum. 1990;33(8):1088-93. https://doi.org/10.1002/art.1780330805.

31. Arend WP, Michel BA, Bloch DA, Hunder GG, Calabrese LH, Edworthy SM, et al. The American College of Rheumatology 1990 criteria for the classification of Takayasu arteritis. Arthritis Rheum. 1990;33(8):1129-34. https://doi.org/10.1002/art.1780330811.

32. Kermani TA, Warrington KJ, Cuthbertson D, Carette S, Hoffman GS, Khalidi $N A$, et al. Disease relapses among patients with giant cell arteritis: a prospective, longitudinal cohort study. J Rheumatol. 2015;42(7):1213-7. https://doi.org/10.3899/jrheum.141347.

33. Stone JH. Limited versus severe Wegener's granulomatosis. Arthritis Rheum. 2003:48(8):2299-309. https://doi.org/10.1002/art.11075.

34. Stone JH, Hoffman GS, Merkel PA, Min YI, Uhlfelder ML, Hellmann DB, et al. A disease-specific activity index for Wegener's granulomatosis: modification of the Birmingham Vasculitis Activity Score. International Network for the Study of the Systemic Vasculitides (INSSYS). Arthritis Rheum. 2001;44(4):91220. https://doi.org/10.1002/1529-0131(200104)44:4<912::AID-ANR148>3.0. $\mathrm{CO} ; 2-5$.

35. Hu N, Westra J, Rutgers A, der Meer BDV, Huitema MG, Stegeman CA, et al. Decreased CXCR1 and CXCR2 expression on neutrophils in anti-neutrophil cytoplasmic autoantibody-associated vasculitides potentially increases neutrophil adhesion and impairs migration. Arthritis Res Ther. 2011;13(6): R201. https://doi.org/10.1186/ar3534.

36. Sada KE, Yamamura M, Harigai M, Fujii T, Dobashi H, Takasaki Y, et al. Classification and characteristics of Japanese patients with antineutrophil cytoplasmic antibody-associated vasculitis in a nationwide, prospective, inception cohort study. Arthritis Res Ther. 2014;16(2):R101. https://doi.org/1 $0.1186 / a r 4550$

37. Monach PA, Warner RL, Tomasson G, Specks U, Stone JH, Ding L, et al. Serum proteins reflecting inflammation, injury and repair as biomarkers of disease activity in ANCA-associated vasculitis. Ann Rheum Dis. 2013;72(8): 1342-50. https://doi.org/10.1136/annrheumdis-2012-201981.

38. Wang JG, Collinge M, Ramgolam V, Ayalon O, Fan XC, Pardi R, et al. LFA-1dependent HuR nuclear export and cytokine mRNA stabilization in T cell activation. J Immunol. 2006;176(4):2105-13. https://doi.org/10.4049/ jimmunol.176.4.2105.

39. Edelmann B, Gupta N, Schnoeder TM, Oelschlegel AM, Shahzad K Goldschmidt J, et al. JAK2-V617F promotes venous thrombosis through $\beta 1 /$ $\beta 2$ integrin activation. J Clin Invest. 2018;128(10):4359-71. https://doi.org/1 $0.1172 / \mathrm{JC} 190312$

40. Argollo M, Fiorino G, Hindryckx P, Peyrin-Biroulet L, Danese S. Novel therapeutic targets for inflammatory bowel disease. J Autoimmun. 2017;85: 103-16. https://doi.org/10.1016/j.jaut.2017.07.004

41. Feagan BG, Rutgeerts P, Sands BE, Hanauer S, Colombel JF, Sandborn WJ, et al. Vedolizumab as induction and maintenance therapy for ulcerative colitis. N Engl J Med. 2013;369(8):699-710. https://doi.org/10.1056/ NEJMoa1215734.

42. Sandborn WJ, Feagan BG, Rutgeerts P, Hanauer S, Colombel JF, Sands BE, et al. Vedolizumab as induction and maintenance therapy for Crohn's disease. N Engl J Med. 2013;369(8):711-21. https://doi.org/10.1056/ NEJMoa1215739.

43. Polman $\mathrm{CH}, \mathrm{O}$ 'Connor PW, Havrdova E, Hutchinson M, Kappos L, Miller DH, et al. A randomized, placebo-controlled trial of natalizumab for relapsing multiple sclerosis. N Engl J Med. 2006;354(9):899-910. https://doi.org/10.1 056/NEJMoa044397.

44. Gordon FH, Lai CW, Hamilton Ml, Allison MC, Srivastava ED, Fouweather MG, et al. A randomized placebo-controlled trial of a humanized monoclonal antibody to alpha4 integrin in active Crohn's disease. Gastroenterology. 2001;121(2):268-74. https://doi.org/10.1053/gast.2001.26260.

45. Gordon KB, Papp KA, Hamilton TK, Walicke PA, Dummer W, Li N, et al. Efalizumab for patients with moderate to severe plaque psoriasis: a randomized controlled trial. JAMA. 2003;290(23):3073-80. https://doi.org/1 0.1001/jama.290.23.3073.

46. Smith CH, Anstey AV, Barker JN, Burden AD, Chalmers RJ, Chandler DA, et al. British Association of Dermatologists' guidelines for biologic interventions for psoriasis. Br J Dermatol. 2009;161(5):987-1019. https://doi.org/10.1111/ j.1365-2133.2009.09505.x.

47. Shima M, Hanabusa H, Taki M, Matsushita T, Sato T, Fukutake K, et al. Factor VIII-mimetic function of humanized bispecific antibody in hemophilia A. N Engl J Med. 2016;374(21):2044-53. https://doi.org/10.1056/NEJMoa1511769.

48. Thomas GD, Hamers AAJ, Nakao C, Marcovecchio P, Taylor AM, McSkimming $C$, et al. Human blood monocyte subsets: a new gating strategy defined using cell surface markers identified by mass cytometry. Arterioscler Thromb Vasc Biol. 2017;37(8):1548-58. https://doi.org/10.1161/A TVBAHA.117.309145

49. Kapellos TS, Bonaguro L, Gemünd I, Reusch N, Saglam A, Hinkley ER, et al. Human monocyte subsets and phenotypes in major chronic inflammatory diseases. Front Immunol. 2019;10:2035. https://doi.org/10.3389/fimmu.2019. 02035.

50. Matsumoto K, Yasuoka H, Yoshimoto K, Suzuki K, Takeuchi T. Platelet CXCL4 mediates neutrophil extracellular traps formation in ANCA-associated vasculitis. Sci Rep. 2021;11:222.

\section{Publisher's Note}

Springer Nature remains neutral with regard to jurisdictional claims in published maps and institutional affiliations. 